\title{
Finite element modelling of elastic intraplate stresses due to heterogeneities in crustal density and mechanical properties for the Jabalpur earthquake region, central India
}

\author{
A Manglik ${ }^{1, *}$, S Thiagarajan ${ }^{1}$, A V Mikhailova ${ }^{2}$ and Yu Rebetsky ${ }^{2}$ \\ ${ }^{1}$ National Geophysical Research Institute, Uppal Road, Hyderabad 500 007, India. \\ ${ }^{2}$ Schmidt Institute of Physics of Earth, 10 B. Gruzinskaya Street 123995 Moscow, Russia. \\ *e-mail: ajay@ngri.res.in
}

\begin{abstract}
Deep lower crustal intraplate earthquakes are infrequent and the mechanism of their occurrence is not well understood. The Narmada-Son-lineament region in central India has experienced two such events, the 1938 Satpura earthquake and the 1997 Jabalpur earthquake, having a focal depth of more than $35 \mathrm{~km}$. We have estimated elastic stresses due to the crustal density and mechanical properties heterogeneities along the Hirapur-Mandla profile passing through the Jabalpur earthquake region to analyse conditions suitable for the concentration of shear stresses in the hypocentral region of this earthquake. Elastic stresses have been computed by a finite element method for a range of material parameters. The results indicate that the shear stresses generated by the density heterogeneities alone are not able to locally enhance the stress concentration in the hypocentral region. The role of mechanical properties of various crustal layers is important in achieving this localization of stresses. Among a range of material parameters analysed, the model with a mechanically strong lower crust overlying a relatively weak sub-Moho layer is able to enhance the stress concentration in the hypocentral region, implying a weaker mantle in comparison to the lower crust for this region of central India.
\end{abstract}

\section{Introduction}

Rheological models of lithosphere integrating the effects of temperature, pressure, and fluids to mechanical deformation have been used extensively to understand tectonic processes and dynamics of lithospheric deformation (Meissner and Strehleau 1982; Chen and Molnar 1983; Kirby 1983; Ranalli 1995). These models are developed by assuming representative rheologies for different crustal layers (quartz and feldspar and other phases) and upper mantle (predominantly olivine) and extrapolating corresponding experimentally-derived steadystate flow laws to natural conditions (Kirby 1983; Ranalli 1995; Kohlstedt et al 1995). A typical model of continental lithosphere having about
$35 \mathrm{~km}$ thick quartz and feldspar dominated crust and olivine dominated upper mantle, and a steady state geotherm representative of Archaean - early Proterozoic age yields a pine-tree-type rheological structure of the lithosphere with a ductile lower crust. More complicated rheological models can be developed depending on the controlling parameters such as temperature, thicknesses and composition of various crustal layers, strain rate, fluid pressure, etc. Despite large uncertainties involved in the estimation and extrapolation of the parameters of empirical flow laws, these models have been successful in deciphering the cut-off depth of intraplate seismicity, assuming that earthquakes occur in the brittle frictional regime and the brittle-ductile transition represents the cut-off

Keywords. Elastic stresses; continental crust; intraplate seismicity; rheology; geodynamics; modelling; seismology. 
depth of intraplate seismicity. The occurrence of earthquakes in the uppermost $20 \mathrm{~km}$ of the crust and then in the mantle lithosphere supported the ductile nature of the lower crust (Chen and Molnar 1983).

The above classical rheological model does not support the occurrence of earthquakes in the lower crust due to its ductile nature inhibiting sufficient stress accumulation leading to seismicity. However, earthquakes in the lower crust have been reported from Africa (Shudofsky et al 1987; Seno and Saito 1994; Foster and Jackson 1998), Baikal rift (Deverchere et al 1991, 2001), Rhine graben (Fuchs et al 1987), North-west America (Wong and Savage 1983; Wong and Chapman 1990), Andean foreland (Smalley and Isacks 1990), northern Switzerland (Diechman 1992), Norway (Bungum et al 1991) and India (Mukherjee 1942; Singh et al 1999). These lower crustal earthquakes have been explained mainly in terms of cold and compositionally strong lower crust depicting brittle instead of ductile behaviour and high strain rate (Shudofsky et al 1987; Wong and Chapman 1990; Doser and Yarwood 1994; Manglik and Singh 2002). In the context of the Indian shield, Manglik and Singh (1991, 1992, 1999) delineated a ductile layer between $32 \mathrm{~km}$ and the Moho for Kolar (low heat flow region) for a normal continental crust whereas the whole lower crust was ductile for high heat flow regions such as Jharia. High surface heat flow of $70-100 \mathrm{~mW} / \mathrm{m}^{2}$ has been reported for the NSL (Ravi Shankar 1988). Manglik and Singh (2002) critically analysed the thermal state of the NSL in view of the lower crustal seismicity and invoked two plausible scenarios to explain the occurrence of the 1997 Jabalpur earthquake at a depth of $36 \pm 2 \mathrm{~km}$ in terms of rheological models. In one scenario, a very low conductive mantle heat flow was assumed while in another scenario, the presence of a compositionally strong (dry granulite type) layer just above the Moho and moderate mantle heat flow was invoked.

A thermally cold lower crust represented by surface heat flow much less than $55 \mathrm{~mW} / \mathrm{m}^{2}$, as used to explain lower crustal seismicity by brittle failure in the above studies, implicitly assumes that the underlying mantle is also cold and, thus, the brittle mantle layer constituted of olivinedominated rheology is thick and mechanically strong (Manglik and Singh 2002). It is, however, difficult to better constrain the nature of the underlying mantle lithosphere from the above rheological modelling. Jackson (2002) inferred the presence of a rheologically weak mantle lithosphere underlying a rheologically strong crust based on relocation of some Himalayan earthquakes and flexure analysis. This is contrary to the mechanical behaviour of the mantle inferred on the basis of the above rheological models explaining lower crustal seismicity. Another approach to resolve the mechanical properties of the mantle lithosphere could be to model intraplate stresses and correlate the stress concentration with seismicity. This approach, along with the constraint that lower crustal earthquakes occur by brittle failure in a mechanically strong lower crust, can help in constraining the mechanical properties of both the lower crust and the mantle lithosphere.

In the present work, we follow the twodimensional elastic stress modelling approach to infer the mechanical properties of the lower crust and the mantle lithosphere of the central Indian shield because this region has experienced two lower crustal earthquakes. A more realistic model of course would be the one that takes into consideration the brittle and the plastic behaviour of various layers and also includes temperature dependence of mechanical properties. However, the present work deals with only elastic stress modelling in which mechanically strong (brittle) and weak (ductile) layers have been simulated by varying the values of the elastic parameters, Young's modulus and Poisson's ratio. We analyse the conditions suitable for the concentration of shear stresses in the hypocentral region of the Jabalpur earthquake by computing intraplate stresses due to crustal density heterogeneities mapped by integrated deep crustal seismic and gravity studies along the Hirapur-Mandla profile passing through this region and variations in the mechanical properties of various layers. Earlier, Mandal et al (1997) carried out elastic stress modelling due to crustal density heterogeneities and topography to analyse the stress concentration in the focal region of the Killari earthquake and Mandal and Singh (1996) carried out stress analysis of the Deccan Volcanic Province. Both these studies were based on the perturbation theory which assumes very small variations in the crustal structure from the layered model.

\section{Tectonic setup and seismicity}

The Narmada-Son Lineament (NSL) in the central Indian shield is a conspicuous tectonic feature cutting across central India (figure 1) and extending more than $1600 \mathrm{~km}$ from the west coast of India. The region consists of horst and graben structures and is bounded by deep faults extending down to the Moho (Kaila et al 1989). Tectonically, this region is considered as a paleo-rift zone, originated during the middle- to late-Achaean period, presently undergoing a compressional stress regime as is evident from the thrust-type focal mechanisms of Broach and Jabalpur earthquakes from 


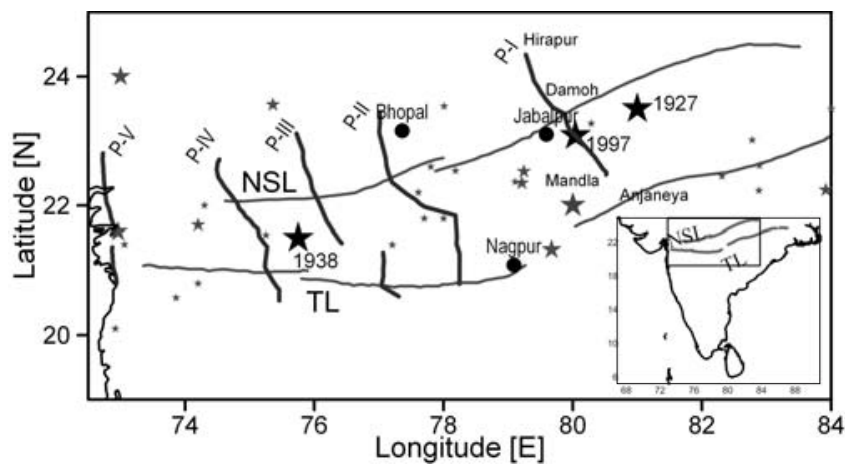

Figure 1. Figure showing distribution of seismicity in the Narmada-Son-Lineament (NSL) region. Epicentral data between 1920 and 2006 shown here have been compiled from ISC (http://www.isc.ac.uk/Bulletin/rectang.html) and NEIC (http://neic.usgs.gov/neis/epic/epic_rect.html) catalogs. The sizes of stars indicate the magnitude of events. Three events shown by large stars are earthquakes with magnitude greater than 6 . Also shown are five deep seismic profiles (P-I to P-V) shot across NSL. Inset shows the location of NSL (modified after Manglik and Singh 2002).

this region. This region is also relatively seismically active (figure 1) compared to the rest of the peninsular shield, having experienced 6 earthquakes of magnitude $\geq 5$ during the last 70 years. The Son Valley (1927, M 6.5), Satpura (1938, M 6.3), Balaghat (1957, M 5.5) and Broach (1970, M 5.4), and Jabalpur (1997, M 6.2) earthquakes are the large events associated with this structure. The available focal depths put Broach earthquake at $11 \mathrm{~km}$ depth (Chung 1993) whereas Satpura and Jabalpur events occurred at a depth of more than $35 \mathrm{~km}$ (Mukherjee 1942; Singh et al 1999). The $40 \mathrm{~km}$ focal depth of the Satpura event can be taken as only suggestive but the focal depth of $36 \pm 2 \mathrm{~km}$ of the Jabalpur earthquake is well constrained (Singh et al 1999). A consistent average Moho depth of about $42 \mathrm{~km}$ in the region has been obtained by deep crustal seismic study (Kaila et al 1987; 1989). Thus, the Jabalpur event is a good example of the lower crustal event.

\section{Crustal structure}

Five deep crustal seismic sounding profiles (figure 1) were shot across the NSL to delineate the crustal structure of this tectonic belt (Kaila et al 1987, 1989). One of these profiles (Profile-I in figure 1) starts from Hirapur in the north of the NSL, passes through Damoh and Jabalpur, and ends at Mandla in the south, covering a total of $240-\mathrm{km}$ distance. Initial interpretation of the travel time seismic data of this profile revealed a graben-horst type structure formed by dissection of the crust into four blocks by the deep faults penetrating up to the Moho (Kaila et al 1987, 1989). Average crustal model obtained by this study broadly consists of upper (depth range $8-18 \mathrm{~km}$ ), middle (depth range $18-32 \mathrm{~km}$ ), and lower (depth range $32-44 \mathrm{~km}$ ) crustal layers of seismic velocity 6.5 , 6.7 , and $6.5 \mathrm{~km} / \mathrm{s}$, respectively. Mall et al (1991) refined these crustal velocity model results and introduced a high velocity layer $(6.75 \mathrm{~km} / \mathrm{s})$ south of Jabalpur at the mid-crustal depth. More recent analyses of the wide-angle seismic data, employing both the travel time and amplitude data, supplemented by the gravity anomalies have delineated a complex upper crustal structure (Murty et al 2004). These results support broadly a four-layered crust with the seismic velocities of 5.8-5.9, 6.5$6.7,6.35-6.40$, and $6.8 \mathrm{~km} / \mathrm{s}$, respectively. Murty et al (2004) interpreted the second layer of 6.5$6.7 \mathrm{~km} / \mathrm{s}$ velocity as an anomalous mafic intrusion within the normal upper crust of seismic velocity of $6.35-6.4 \mathrm{~km} / \mathrm{s}$. The upper crustal layer continues up to a depth of about $20-22 \mathrm{~km}$ where the lower crustal velocity of $6.8 \mathrm{~km} / \mathrm{s}$ is encountered. The depth of the mafic intrusion is highly variable along the profile and it comes to $2 \mathrm{~km}$ depth between Katangi and Jabalpur in the central part of the profile.

The NSL appears as a prominent feature in the gravity map of India, dividing the Indian peninsular shield into two parts, the northern part characterized by relatively positive Bouguer anomaly as compared to the southern part (Verma and Banerjee 1992). The lineament itself appears as a linear elongated gravity anomaly zone extending east-west for almost 800-900 km from the west coast up to the southeast of Jabalpur in central India (Mishra 1992). Verma and Banerjee (1992) interpreted the Bouguer gravity high of the Jabalpur-Mandla section of the profile as a massive high-density intrusive body in the upper crust. They interpreted the presence of such intrusives for other profiles also. Singh and Meissner (1995) alternatively proposed the presence of an underplated layer at the Moho as a source of this gravity high for four profiles (P-II to P-V) west of the HirapurMandla profile. The underplated layer is more than $20-\mathrm{km}$ thick in the western part and thins towards east in their model.

Electrical structure of the crust of the Jabalpur earthquake region was delineated along a 190-kmlong NW-SE trending Damoh-Jabalpur-MandlaAnjaneya MT profile (figure 1) coinciding with the deep crustal seismic profile between Damoh and Mandla (Gokarn et al 2001). The results indicated the presence of a 5 -km-thick layer of the Vindhyan sediments in the Damoh-Katangi region and a relatively low resistivity layer of about $200 \Omega \mathrm{m}$ below the sediments coinciding with the high seismic velocity layer of $6.5 \mathrm{~km} / \mathrm{s}$. Based on these results, 
Gokarn et al (2001) inferred this layer to be the lower crust, as earlier proposed by Kaila et al (1989), and conjectured that the upper crust might have been completely eroded by uplift and erosion processes before the deposition of the Vindhyan sediments. Murty et al (2004), however, considered this high velocity layer as a mafic intrusion instead of lower crust and treated the underlying $6.35-6.4 \mathrm{~km} / \mathrm{s}$ layer as the upper crust, thereby assuming that the upper crust is in fact present beneath this mafic layer. Earlier, Arora et al (1995) reported a conductive body of $5 \Omega \mathrm{m}$ resistivity at a depth of $20-30 \mathrm{~km}$ and a lateral extent of about $100 \mathrm{~km}$ below Jabalpur and Mandla based on thinsheet modelling of the geomagnetic depth sounding (GDS) data. This conductive body correlates with the high-velocity zone interpreted by Mall et al (1991) and the high-density body modelled by Verma and Banerjee (1992).

The delineated crustal structure along the Hirapur-Mandla profile by deep crustal seismic, gravity, and electrical resistivity investigations has been interpreted both in terms of complete erosion of the upper crust and the presence of the upper crust below the high-velocity layer. Since geophysical methods suffer from the problem of non-uniqueness, the use of integrated geophysical methods is expected to give better results. Therefore, we use the crustal structure obtained by Murty et al (2004) based on integrated interpretation of deep crustal seismic and Bouguer gravity anomaly data for the computation of elastic stresses. The ambiguity in the interpretation of the nature of the high velocity layer in the average depth range of $8-15 \mathrm{~km}$ is not expected to affect our analysis as we treat this layer as mechanically strong based on its high seismic velocity and density.

\section{Finite element modelling}

We take the crustal structure along the HirapurMandla profile obtained by Murty et al (2004) based on integrated deep crustal seismic and gravity data (figure 2) to numerically model elastic stresses due to crustal density heterogeneities and mechanical property variations. As discussed in the introduction, we incorporate strong (brittle) and weak (ductile) layers in terms of Young's modulus and Poisson's ratio because it is not possible to incorporate the actual brittle and ductile behaviour in the elastostatic stress modelling carried out here. Nevertheless, the consideration of elastically strong and weak layers in the present modelling will help in capturing the patterns of stress concentration. The crustal model of Murthy et al (2004) provides the structure up to the Moho. We have included a

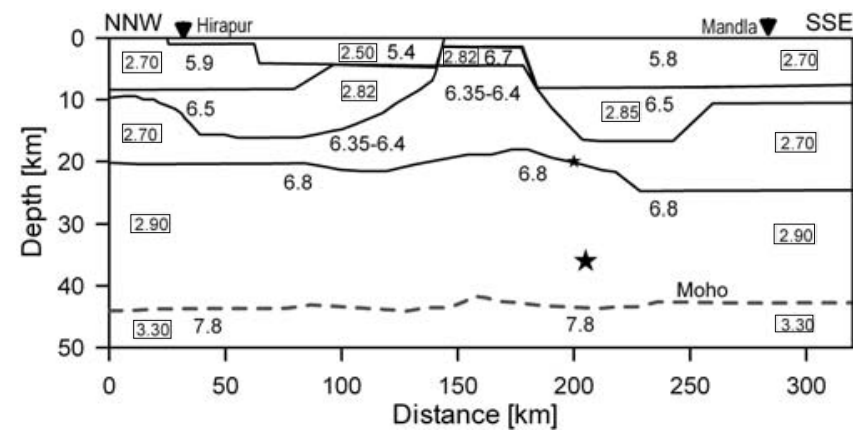

Figure 2. Simplified crustal structure along the HirapurMandla profile (profile P-I in figure 1) obtained by integrated deep crustal seismic and gravity data (after Murty et al 2004). Values in large fonts are $P$-wave velocities in $\mathrm{km} / \mathrm{s}$ and those enclosed in boxes are density in $\mathrm{gm} / \mathrm{cm}^{3}$.

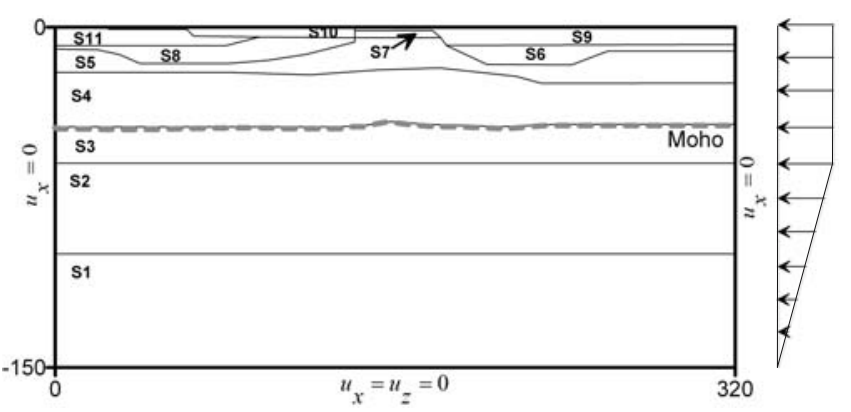

Figure 3. Geometry of the model used for finite element discretization along with boundary conditions at left, right, and bottom boundaries. Also shown is prescribed horizontal displacement boundary condition at the right boundary for the case discussed in section 5.2. The finite element model has been constructed from 11 patches marked as S1-S11. Material parameters of these patches are given in table 1 .

sub-Moho layer up to $60 \mathrm{~km}$ depth and two additional artificial layers with weak elastic parameters (table 1) below $60 \mathrm{~km}$ down to the depth of $150 \mathrm{~km}$ to simulate the effect of lower lithosphere and asthenosphere. This also helps in avoiding any artefacts of the bottom boundary condition on the estimates of stresses at the Moho. The bases of these layers have been assumed to be horizontal in the absence of the lithospheric structure. The model thus generated for the finite element analysis is shown in figure 3 .

The model has been sub-divided into 11 patches and discretized into 3099 plane strain 4-nodes quadrilateral elements and 3211 nodes. We have used plane strain approximation here because the profile is perpendicular to the NSL which is an approximately $1600 \mathrm{~km}$ long tectonic feature and the profile is across this tectonic feature. Elastic material properties for every patch were selected based on seismic velocity, density, and depth of various layers (table 1). Young's modulus lies in the range of $10^{10}-10^{12} \mathrm{~Pa}$.s for crustal rocks (Zuber 
et al 1989; Pauselli and Federico 2003; Dyksterhuis and Mueller 2004). This can be estimated from seismic $P$-wave velocity and density values of various rocks using the following relationship (Pauselli and Federico 2003):

$$
E=\rho V_{P}^{2} \frac{(1+\nu)(1-2 \nu)}{3 \nu}
$$

where $E, \nu, \rho, V_{P}$ are Young's modulus, Poisson's ratio, density, and seismic $P$-wave velocity, respectively. For the density and seismic velocity values available for our model, we get Young's modulus values in the range of $5-20 \times 10^{10}$ Pa.s assuming Poisson's ratio of 0.25 . Since pressure and temperature both increase with the depth, the elastic parameters should be corrected for these effects. We indirectly incorporate the thermal effect in terms of reduction of Young's modulus of the mid-crustal layer by assuming that the temperature increase would result in a decrease in the value of Young's modulus. This correction is somewhat arbitrary. Nevertheless the $10^{10}-10^{12}$ order of the magnitude of the Young's modulus is maintained. For example, the upper crustal layer (S9, S11) has been considered as being stronger in comparison to the mid-crustal layer (S5) although both have the same density values and S5 has a higher velocity in comparison to S9 and S11. Murty et al (2004) considered the layer S5 as the upper crustal layer. From rheological considerations, an upper crustal layer with quartz-dominated rheology when buried at a depth of $15-20 \mathrm{~km}$ would be mechanically weaker than when it is placed within the top $10 \mathrm{~km}$ depth. Therefore, we have considered this layer as mechanically weak and assigned a lower value of Young's modulus. Similarly, the high velocity layer (S6, S7, S8) has been considered as a mechanically strong layer keeping in view its lower crustal affinity/mafic intrusion nature (Mall et al 1991; Murthy et al 2004) and its shallow depth. Computations have been carried out by using an FEM package UWay (Vlasov et al 2000, 2004). This package has options for numerical estimation of stress-strain state and mechanical behaviour of soil and consolidate rocks, homogeneous and heterogeneous media, and composite materials.

\section{Numerical results}

We analyse various cases to arrive at a model that is able to show the concentration of shear stress in the hypocentral region of the 1997 Jabalpur earthquake. Numerical results for different cases are discussed below.

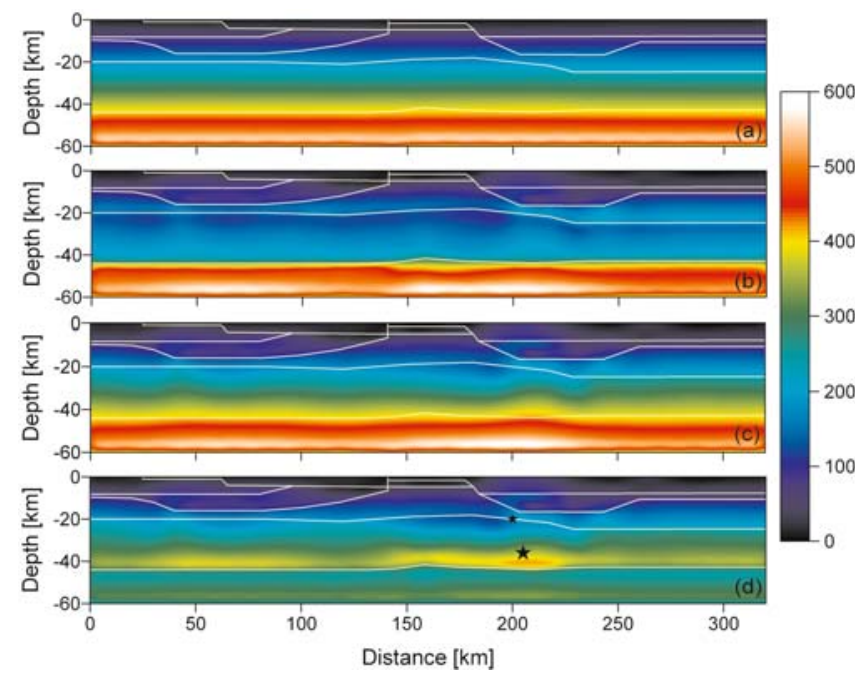

Figure 4. Computed maximum shear stresses in $\mathrm{MPa}$ for various model cases: (a) only density heterogeneities, (b) both density and mechanical property variations for elastically weak lower crust and strong upper mantle, (c) same as (b) but with elastically strong lower crust, and (d) strong lower crust and weak upper mantle. Large star represents the focal depth of the 1997 Jabalpur earthquake and small star corresponds to the 2001 Jabalpur earthquake.

\subsection{Stresses due to gravity load}

In the first model (M01), the effect of only density heterogeneities is analysed. Here, material parameters of all the layers, excluding the bottom two layers, have been fixed at $E=1.0 \times 10^{10} \mathrm{~Pa} . \mathrm{s}$ and $\nu=0.25$. For this gravity loading case, no displacement condition $\left(u_{x}=u_{z}=0\right)$ has been applied at the bottom boundary of the model. This boundary is at a depth of $150 \mathrm{~km}$ and the layer just above this boundary (S1) is mechanically very weak to avoid the influence of this boundary on the stresses computed for the top $60 \mathrm{~km}$ of the model. The side boundaries impose the condition of no horizontal displacement $\left(u_{x}=0\right)$ and only vertical displacement $\left(u_{z}\right)$ is allowed. The one-dimensional nature of the crustal structure at both sides of the model supports this boundary condition as the applied load is due to the gravity. The computed maximum shear stress $(\tau)$ is shown in figure 4(a). Crustal structure is also superimposed. The results indicate an increase in the value of $\tau$ with depth with the maximum value of about $550 \mathrm{MPa}$ at a depth of $56-58 \mathrm{~km}$. There is no remarkable lateral variation in $\tau$ due only to density variations.

In the next model (M02), material properties of lower crustal and upper mantle layers are so chosen that these represent a mechanically weak lower crust $\left(E=1.0 \times 10^{11}\right.$ Pa.s, $\left.\nu=0.38\right)$ overlying a mechanically strong sub-Moho lithosphere $\left(E=1.0 \times 10^{12}\right.$ Pa.s, $\left.\nu=0.25\right)$. Material properties of other layers are given in table 1 . This model 
Table 1. Material properties assigned to various layers.

\begin{tabular}{llcccc}
\hline \multicolumn{1}{c}{ Region } & Patch no. & $\begin{array}{c}E \\
\left(\times 10^{10} \text { Pa.s }\right)\end{array}$ & $\nu$ & $\begin{array}{c}\text { Density } \\
{\left[\mathrm{kg} / \mathrm{m}^{3}\right]}\end{array}$ & $\begin{array}{c}V_{p} \\
{[\mathrm{~km} / \mathrm{s}]}\end{array}$ \\
\hline Vindhyans & $\mathrm{S} 10$ & 2 & 0.25 & 2500 & 5.50 \\
Upper crust & $\mathrm{S} 9, \mathrm{~S} 11$ & 10 & 0.25 & 2700 & 5.90 \\
High velocity layer & $\mathrm{S} 6, \mathrm{~S} 7, \mathrm{~S} 8$ & 50 & 0.25 & 2820 & 6.50 \\
Middle crust & $\mathrm{S} 5$ & 2 & 0.25 & 2700 & 6.35 \\
Lower crust* & $\mathrm{S} 4$ & 100 & 0.25 & 2900 & 6.80 \\
Sub-Moho lithosphere & $\mathrm{S} 3$ & 10 & 0.38 & 3300 & 7.80 \\
Lower lithosphere & $\mathrm{S} 2$ & 0.8 & 0.45 & 2350 & $\ldots$ \\
Asthenosphere & $\mathrm{S} 1$ & 0.1 & 0.499 & 3400 & $\ldots$ \\
\hline
\end{tabular}

${ }^{*}$ Values of these two layers vary in various models analysed.

has been selected to represent a case similar to the rheological stratification of a typical continental lithosphere in which a weak, ductile lower crust rests on the top of a strong, brittle upper mantle. Here, elastically strong sub-Moho lithosphere and elastically weak lower crust can be correlated with the brittle upper mantle and ductile lower crust, respectively, of a rheological model. The results of $\tau$ for this case, shown in figure 4(b), indicate a decrease in $\tau$ in the depth range of $20-40 \mathrm{~km}$ and an enhancement in $\tau$ at the depth $>50 \mathrm{~km}$ in comparison with the previous model. The maximum shear stress reaches to $575 \mathrm{MPa}$ at the depth of 56 $58 \mathrm{~km}$ and there are significant lateral variations in $\tau$ at different depth levels. Thus, variations in the mechanical property of various layers seem to have a profound effect on the shear stress distribution. Nevertheless this model is unable to produce the concentration of shear stress in the hypocentral region of the 1997 Jabalpur earthquake. Lateral variations in the shear stress are also seen in the upper and middle crust.

Further, we analyse a scenario (Model M03) in which both the lower crust and the upper mantle have strong mechanical properties $\left(E=1.0 \times 10^{12}\right.$ Pa.s, $\nu=0.25$ for both the layers $)$ keeping material properties of other layers the same as in M02. For this case shown in figure 4(c), the magnitude of $\tau$ in the lower crust increases by about $100 \mathrm{MPa}$ in comparison to M02 but the maximum shear stress is once again confined to the sub-Moho lithosphere.

The last model (M04) consists of a strong lower crust $\left(E=1.0 \times 10^{12} \mathrm{~Pa} . \mathrm{s}, \quad \nu=0.25\right)$ resting on a weak upper mantle $\left(E=1.0 \times 10^{11} \mathrm{~Pa} . \mathrm{s}\right.$, $\nu=0.38$ ). Material properties of other layers are the same as given in table 1. Computed $\tau$ for this case, shown in figure 4(d), reveals a zone of high stress concentration in the lower crust in the hypocentral region (large star) of the 1997 earthquake. The shear stress in this zone is about 60 $80 \mathrm{MPa}$ higher than the background shear stress of 330-350 MPa. Shear stress in the upper mantle layer is much smaller than that obtained for previous models. Another earthquake of 2000.10.16 at a depth of $20 \mathrm{~km}$ (small star) in the same region also falls in a zone where a perturbation in the computed shear stress is observed. This model shows a good correlation between the shear stress concentration/perturbation and the lower crustal seismicity.

\subsection{Stresses due to imposed horizontal displacement}

The above models incorporated only the effect of gravity loading due to density heterogeneities and mechanical properties variations. We have further computed the stresses induced in the crust as a result of horizontal plate tectonic forces. Two models, one having a weak lower crust resting on a strong upper mantle (M02), and the other having a strong lower crust resting on a weak upper mantle (M04) have been considered here. A horizontal plate tectonic force is applied in terms of specified displacement at the right boundary (figure 3). This displacement has a constant value of $30 \mathrm{~m}$ up to a depth of $60 \mathrm{~km}$, below which it decreases linearly to zero at the bottom of the computation box. The value of $30 \mathrm{~m}$ has been arrived at by considering the probable magnitude of the plate tectonic forces. Coblentz et al (1998) used values of $2 \times 10^{12} \mathrm{~N} / \mathrm{m}$ and $4 \times 10^{12} \mathrm{~N} / \mathrm{m}$ for the ridge push and compressional force at the Himalayan collision boundary, respectively, in the modelling of the stress field of the Indian plate. This results in an average stress magnitude of 20-40 MPa. We use an average value of the above two to represent the plate tectonic force in the plate interior which yields on average $30 \mathrm{MPa}$ stress. The $30 \mathrm{~m}$ displacement results in this stress level. Similar magnitude of regional maximum compressive stress was used by Mandal et al (1997) in the elastic stress modelling of the Killari earthquake region. The in situ 


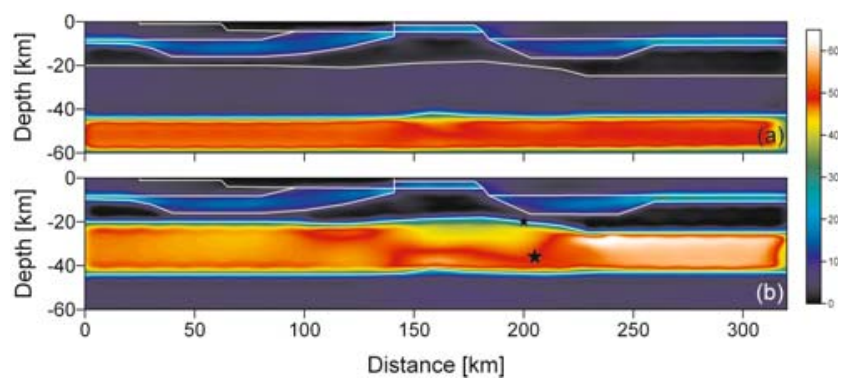

Figure 5. Computed maximum shear stresses in MPa for the case of prescribed horizontal displacement at the right boundary to simulate plate tectonic stresses. (a) elastically weak lower crust on strong upper mantle, and (b) strong lower crust and weak upper mantle.

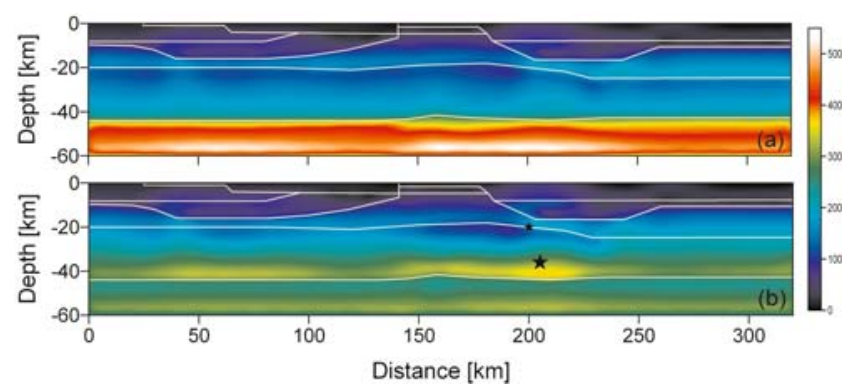

Figure 6. Maximum shear stresses in MPa after combining gravity stress shown in figure 4 and tectonic stress shown in figure 5 for the cases (a) weak lower crust, and (b) strong lower crust and weak upper mantle.

stress measurements in the Indian shield and focal mechanisms of intraplate earthquakes suggest a mainly $\mathrm{N}-\mathrm{S}$ direction of the maximum horizontal compression (Gowd et al 1992). Therefore, the horizontal displacement boundary condition applied in the present model is in good agreement with the direction of the maximum compressive stress in the Indian shield as the profile is almost NNWSSE. We have considered a uniform displacement up to $60 \mathrm{~km}$ depth and then a linearly decreasing displacement keeping in view the mechanical properties of the lower lithosphere and the underlying asthenosphere. The boundary conditions at the left and bottom boundaries are the same as used for the previous case of gravity loading.

Computed distribution of $\tau$ for both the cases are shown in figure 5. Lateral variations in mechanical properties have a profound effect on the distribution of stresses. For the first case (figure 5a), concentration of large stresses is obtained within the upper lithosphere at the depth $>40 \mathrm{~km}$. There is very little shear stress in the mid-crustal layer (S5) and lateral perturbations of about $10 \mathrm{MPa}$ are observed within the high velocity layer (S6, S7, S8 in figure 3). The next model with a strong lower crust (figure $5 \mathrm{~b}$ ) shows a very different distribution of $\tau$. In this model, $\tau$ is large within the lower

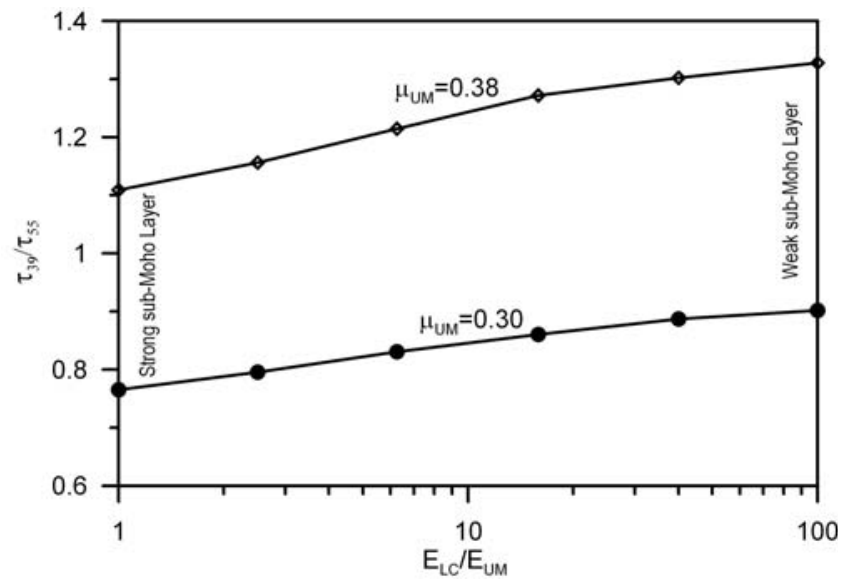

Figure 7. The effect of variations in the elastic parameters of the lower crust $\left(E_{\mathrm{LC}}, \nu_{\mathrm{LC}}\right)$ and sub-Moho layer $\left(E_{\mathrm{UM}}, \nu_{\mathrm{UM}}\right)$ on the concentration of maximum shear stress in the focal region of the lower crustal Jabalpur earthquake. Full details are described in the text.

crust. The hypocentral region (large star) falls in the region of large shear stress. Nevertheless the shear stresses produced by an imposed horizontal displacement of $30 \mathrm{~m}$ is much smaller than the shear stresses produced by gravity loading.

Combining shear stresses produced by horizontal displacement with the shear stresses due to the gravity loading does not change the distribution significantly for the lower crust (figure 6). However, there is very small change in the shear stress distribution in the hypocentral region of 2000.10.16 earthquake (small star in figure 6b).

\section{Discussion and conclusion}

The occurrence of intraplate seismicity in the lower crust can be used as an important constraint for mechanical models of continental lithosphere. Rheological models of continental lithosphere explain the lower crustal intraplate seismicity mainly in terms of cold and brittle lower crust under the assumption that earthquakes occur by frictional failure in the brittle regime. These models implicitly indicate a mechanically strong mantle lithosphere. Earlier work of Manglik and Singh (2002) on the lower crustal 1997 Jabalpur earthquake inferred low-to-moderate mantle heat flow in the NSL leading to a mechanically strong and brittle lower crust. We have analysed the mechanical properties of both the lower crust and the mantle lithosphere through elastic stress modelling. Our elastic stress modelling results indicate that the localized concentration of shear stresses at the lower crustal depths of more than $35 \mathrm{~km}$ can be attained only when the lower crust is mechanically strong in comparison to the underlying mantle 
lithosphere for elastic rheology. Thus, the present study provides a constraint on the mechanical properties of the mantle lithosphere by implying that it should be mechanically weak. This is further analyzed in figure 7 .

In figure 7, we vary Young's Modulus (E) and Poisson's ratio $\nu$ for the lower crust (layer S4) and sub-Moho layer (layer S3) keeping all the other parameters the same as used for the model M04. Here $\left(E_{\mathrm{LC}}, \nu_{\mathrm{LC}}\right)$ and $\left(E_{\mathrm{UM}}, \nu_{\mathrm{UM}}\right)$ are Young's modulus and Poisson's ratio of S4 (lower crust (LC)) and S3 (mantle lithosphere (UM)), respectively. $\tau_{39}, \tau_{55}$ are maximum shear stresses at a depth of 39 and $55 \mathrm{~km}$, respectively, at the lateral profile distance of $210 \mathrm{~km}$, which corresponds to the region of maximum stress concentration in our model. The depth $39 \mathrm{~m}$ is above the Moho whereas $55 \mathrm{~km}$ is below the Moho. The value of Young's modulus of the lower crust increases from left to right and two curves marked by solid circles and diamonds correspond to two values of Poisson's ratio $\nu_{\mathrm{UM}}$ of the upper mantle, a higher value of which implies a weaker elastic rheology. $\nu_{\mathrm{LC}}$ is taken as 0.25 . The results indicate that a moderate increase in $\nu_{\mathrm{UM}}$ to 0.30 from the standard value of 0.25 does not enhance the ratio $\tau_{39} / \tau_{55}$ to make it larger than 1 . It means that the maximum shear stress in the mantle lithosphere (S3) is still larger than the shear stress in the lower crustal layer (S4) even though Young's Modulus of the lower crust is increased by two orders of magnitude. The larger concentration of the shear stress in the lower crust in comparison to that in S3 is seen when $\nu_{\mathrm{UM}}$ is further increased to 0.38 , implying that the sub-Moho layer should be sufficiently weak for the stress concentration to take place in the lower crust. The results also indicate that variation in Young's modulus has only moderate effect on shear stress concentration whereas Poisson's ratio has a more profound effect.

To summarise, the shear stresses generated by density heterogeneities alone are not able to locally enhance the shear stress concentration in the hypocentral region of the lower crustal Jabalpur earthquake of 1997. The role of mechanical properties of various crustal layers is important in achieving this localization of shear stresses. Among a range of material parameters analysed in the present elastic stress modelling, the model with a mechanically strong lower crust overlying a relatively weak sub-Moho layer is able to enhance the stress concentration in the hypocentral region, implying a weaker mantle in comparison to the lower crust for this region of central India. The mechanically strong lower crust is indicative of a dry granulite type rheology but even more interesting would be to understand what causes the mantle lithosphere of this region to behave as a relatively weak material in comparison to the lower crust. One possibility could be the presence of fluids in the sub-Moho layer which should reflect in $P$ - and $S$-wave seismic velocities, attenuation factor, and electrical conductivity of the lower crust and upper mantle surrounding the hypocentral region. The $P$-wave seismic velocity of $7.8 \mathrm{~km} / \mathrm{s}$ of the sub-Moho layer in this region (Murty et al 2004 ) is lower than the seismic velocity of 8.0$8.1 \mathrm{~km} / \mathrm{s}$ representative of a normal continental mantle lithosphere. However, a detailed and high resolution integrated geophysical mapping of the hypocentral region is needed to more conclusively determine the nature of the upper mantle of this region.

\section{Acknowledgements}

This work was supported by Department of Science and Technology, India, and Russian Academy of Sciences, Russia, under the framework of Indo-Russian programme of collaboration (ILTP). Authors are grateful to Area Chairman of ILTP (Seismology), and to Director, NGRI, Hyderabad, and Director General, IPE, Moscow, for their support. The manuscript has been greatly benefited by the stimulating comments of two anonymous reviewers.

\section{References}

Arora B R, Waghmare S Y and Mahashabde M V 1995 Geomagnetic depth sounding along the Hirapur-MandlaBhandara profile, Central India; Geol. Soc. India Memoir 31 519-535.

Bungum H, Alsaker A, Kvamme L B and Hansen R A 1991 Seismicity and seismotectonics of Norway and nearby continental shelf areas; J. Geophys. Res. 96 2249-2265.

Chen W P and Molnar P 1983 Focal depths of intracontinental and intraplate earthquakes and their implications for the thermal and mechanical properties of the lithosphere; J. Geophys. Res. 88 4183-4214.

Chung W Y 1993 Source parameters of two riftassociated intraplate earthquakes in peninsular India: The Bhadrachalam earthquake of April 13, 1969 and the Broach earthquake of March 23, 1970; Tectonophys. 225 219-230.

Coblentz D D, Zhou S, Hillis R R, Richardson R M and Sandiford M 1998 Topography, boundary forces, and the Indo-Australian intraplate stress field; J. Geophys. Res. 103 919-931.

Deichmann N 1992 Structural and rheological implications of lower crustal earthquakes below northern Switzerland; Phy. Earth. Planet. Int. 69 270-280.

Deverchere J, Houdry F, Diament M, Solonenko N V and Solonenko A V 1991 Evidence for a seismogenic upper mantle and lower crust in the Baikal rift; Geophys. Res. Lett. 18 1099-1102.

Deverchere J, Petit C, Gileva N, Radziminovitch N, Melnikova V and San'Kov V 2001 Depth distribution of earthquakes in the Baikal rift system and its implications for the rheology of the lithosphere; Geophys. J. Int. 146 $714-730$. 
Doser D I and Yarwood D R 1994 Deep crustal earthquakes associated with continental rifts; Tectonophys. $\mathbf{2 2 9}$ 123-131.

Dyksterhuis S and Mueller R D 2004 Modelling the contemporary and palaeo stress field of Australia using finiteelement modelling with automatic optimization; Explor. Geophys. 35 236-241.

Foster A N and Jackson J A 1998 Source parameters of large African earthquakes: implications for crustal rheology and regional kinematics; Geophys. J. Int. 134 422-448.

Fuchs K, Bonjer K-P, Gajewski D, Lueschen E, Prodehl C, Sandmeier K-J, Wenzel F and Wilhelm H 1987 Crustal evolution of the Rhinegraben area. 1. Exploring the lower crust in the Rhinegraben rift by unified geophysical experiments; Tectonophys. 141 261-275.

Gokarn S G, Rao C K, Gupta G, Singh B P and Yamashita M 2001 Deep crustal structure in central India using magnetotelluric studies; Geophys. J. Int. 144 685-694.

Gowd T N, Srirama Rao S V and Gaur V K 1992 Tectonic stress field in the Indian subcontinent; J. Geophys. Res. 97 11,879-11,888.

Jackson J 2002 Strength of the continental lithosphere: Time to abandon the jelly sandwich?; GSA Today 12(9) 4-9.

Kaila K L, Murty P R K, Mall D M, Dixit M M and Sarkar D 1987 Deep seismic sounding along Hirapur-Mandla Profile, Central India; Geophys. J. R. Astr. Soc. 89 399-404.

Kaila K L, Murthy P R K and Mall D M 1989 The evolution of Vindhyan basin vis-à-vis the Narmada-Son lineament, central India; Tectonophys. 162 277-289.

Kirby S H 1983 Rheology of the lithosphere; Rev. Geophys. Space Phys. 21 1458-1487.

Kohlstedt D L, Evans B and Mackwell S J 1995 Strength of the lithosphere: Constraints imposed by laboratory experiments; J. Geophys. Res. 100 17,587-17,602.

Mall D M, Kaila K L and Rao V K 1991 Magnetic Body Interpreted at mid-crustal Level between Jabalpur and Mandla as an Indicator for the Source Regions for Deccan Basalt; In: Proc. 1st Int. Symp. \& Exhibition on 'Exploration Geophysics in Nineteen Nineties', Assoc. Expl. Geophysicists, Hyderabad, India.

Mandal P and Singh R N 1996 Three dimensional intraplate stress distribution associated with topography and crustal density inhomogeneities beneath the Deccan Volcanic Province; Proc. Indian Acad. Sci. (Earth Planet. Sci.) 105 143-156.

Mandal P, Manglik A and Singh R N 1997 Intraplate stress distribution induced by topography and crustal density heterogeneities beneath the Latur, India, region; J. Geophys. Res. 102 11,719-11,729.

Manglik A and Singh R N 1991 Rheology of Indian continental crust and upper mantle; Proc. Indian Acad. Sci. (Earth Planet. Sci.) $100389-398$.

Manglik A and Singh R N 1992 Rheological thickness and strength of the Indian continental lithosphere; Proc. Indian Acad. Sci. (Earth Planet. Sci.) 101 339-345.

Manglik A and Singh R N 1999 Rheological stratification of the Indian continental lithosphere: Role of diffusion creep; Proc. Indian Acad. Sci. (Earth Planet. Sci.) 108 15-21.

Manglik A and Singh R N 2002 Thermomechanical structure of the central Indian shield: Constrains from deep crustal seismicity; Curr. Sci. 82 1151-1157.
Meissner R and Strehleau J 1982 Limits of stresses in continental crust and their relation to the depth-frequency distribution of shallow earthquakes; Tectonics 1 73-89.

Mishra D C 1992 Mid-continent gravity 'high' of central India and the Gondwana tectonics; Tectonophys. 212 153-161.

Mukherjee S M 1942 Seismological features of the Satpura earthquake of the $14^{\text {th }}$ March 1938; Proc. Indian Acad. Sci. 16 167-175.

Murty A S N, Tewari H C and Reddy P R 2004 2-D Crustal velocity structure along Hirapur-Mandla profile in central India: An update; Pure Appl. Geophys. 161 165-184.

Pauselli C and Federico C 2003 Elastic modelling of the Alto Tiberina normal fault (central Italy): geometry and lithological stratification influences on the local stress field; Tectonophys. 374 99-113.

Ranalli G 1995 Rheology of the earth; Springer $2^{\text {nd }}$ edn, 436pp.

Ravi Shankar 1988 Heat flow map of India and discussion on its geological and economic significance; Indian Minerals $4288-110$

Seno T and Saito A 1994 Recent East African earthquake in the lower crust; Earth Planet. Sci. Lett. 121 125-136.

Shudofsky G N, Cloetingh S, Stein S and Wortel R 1987 unusually deep earthquakes in East Africa: Constraints on the thermo-mechanical structure of a continental rift system; Geophys. Res. Lett 14 741-744.

Singh A P and Meissner R 1995 Crustal configuration of the Narmada-Tapti region (India) from gravity studies; J. Geodynamics 20 111-127.

Singh S K, Dattatrayam R S, Shapiro N M, Mandal P, Pacheco J F and Midha R K 1999 Crust and upper mantle structure of the peninsular India and source parameters of May 21, 1997 Jabalpur earthquake $(\mathrm{Mw}=5.8)$ Results from a new regional broadband network; Bull. Seismol. Soc. Am. 89 1631-1641.

Smalley R and Isacks B L 1990 Seismotectonics of thinand thick-skinned deformation in the Andean foreland from local network data: Evidence for a seismogenic lower crust; J. Geophys. Res. 95 12,487-12,498.

Verma R K and Banerjee P 1992 Nature of continental crust along the Narmada-Son lineament, inferred gravity and deep seismic sounding data; Tectonophys. 202 375-397.

Vlasov A N, Mnushkin M G and Yanovsky Yu G 2000 Object-oriented approach in programming of finite element method; In: Proc. $3^{\text {rd }}$ Int. Conf. on Advances of Computer Methods in Geotechnical and Geoenvironmental Engineering (ed.) S A Yufin; pp. 367-372. A. A. Balkema Publ. Co.

Vlasov A N, Yanovsky Yu G, Mnushkin M G and Popov A A 2004 Solving geomechanical problems with UWay FEM package; In: Computational Methods in Engineering and Science (ed.) V P Iu; pp. 453-461. Taylor \& Francis.

Wong I G and Savage W U 1983 Deep intraplate seismicity in the western Sierra Nevada, central California; Bull. Seismol. Soc. Am. 73 797-812.

Wong I G and Chapman D S 1990 Deep intraplate earthquakes in the Western United States and their relationship to lithospheric temperatures; Bull. Seismol. Soc. Am. 80 589-599.

Zuber M T, Bechtel T D and Forsyth D W 1989 Effective elastic thickness of the lithosphere and mechanism of isostatic compensation in Australia; J. Geophys. Res. 94 9353-9367. 